\title{
Impact of COVID-19 Lockdown on Dietary Behavior Related to Oral Health in Teesside, United Kingdom
}

\author{
Rachael England, Lawrence A. Nnyanzi, Fatemeh Vida Zohoori
}

\section{ABSTRACT}

Diet is well established as a significant etiological factor in oral diseases, particularly dental caries, and dental erosion. During the COVID-19 pandemic, the stay-at-home orders (lockdown) impacted people's wellbeing. Emotional distress affects food preferences and consumption. Therefore, this study aimed to understand the dietary changes due to lockdown in Teesside and consequently its impact on oral health.

Method: An online survey was developed based on the World Health Organization Adult Oral Health Survey. After obtaining ethical approval, the survey was distributed among residents $\geq 18 \mathrm{y}$ living in Teesside. The questions addressed dietary choices before and during the lockdown. Participants were also invited to a semi-structured interview to understand the influence of lockdown on dietary choices.

Results: The frequency of consuming daily fresh fruit decreased by $3.2 \%$. Participants consuming cakes and biscuits 2-3 times daily doubled from $5.4 \%$ to $10.6 \%$. The daily consumption of sweets increased from $8.6 \%$ to $14.9 \%$. Drinking alcohol four or more times per week increased from $7.1 \%$ to $12.5 \%$. The most common explanations were reliance on online grocery shopping, lack of social interaction, and working from home.

Conclusion: Support strategies are needed for communities to maintain healthy nutritional choices during periods of significant upheaval.

Published Online: January 24, 2022

ISSN: $2684-4443$

DOI : 10.24018/ejdent.2022.3.1.129

\section{R. England*}

School of Health and Life Sciences, Teesside University, Middlesbrough, United Kingdom.

(e-mail: rengland@fdiworlddental.org) L. A. Nnyanzi

School of Health and Life Sciences, Teesside University, Middlesbrough, United Kingdom.

(e-mail: 1.nnyanzi@tees.ac.uk)

F. V. Zohoori

School of Health and Life Sciences, Teesside University, Middlesbrough, United Kingdom.

(e-mail: v.zohoori@tees.ac.uk)

*Corresponding Author

Keywords: COVID-19, diet, lockdown, oral diseases.

\section{INTRODUCTION}

Diet is well established as a significant etiological factor in oral diseases, particularly dental caries and dental erosion [1]. Dental caries occurs due to dental biofilm (plaque) metabolizing sugars in the diet into organic acids, which cause the demineralization of tooth enamel. Similarly, dietary acids found in fruit, fruit juice and carbonated beverages lead to a progressive and permanent erosion of tooth enamel [1], [2]. In addition, frequent alcohol consumption, especially when combined with tobacco intake, is associated with an increased risk of oral and oropharyngeal cancer [3]. The COVID-19 pandemic led to all non-essential businesses, including dental clinics, being ordered to close, and people told to "stay at home" [4]. The closure of businesses led to panic buying, with many essential products quickly becoming unavailable [5]. The stay-at-home orders (lockdown) were in place for three months, with many businesses shifting to a work from home model. The pandemic and lockdown had a serious effect on people's mental health and wellbeing due to the isolation, uncertainty and stress [6]. Stress has long been associated with "comfort eating", that is, the consumption of high fat, high sugar, high-calorie foods and drinks in response to negative emotions [7].

The Institute for Fiscal Studies [8] used data from supermarkets, restaurants, and other sources to assess the dietary changes of the United Kingdom (UK) population during the lockdown. Their findings showed that on average, people were consuming $15 \%$ more calories than normal, and this remained $10 \%$ higher than average for the rest of 2020 [8]. A comparison of nutritional habits between the UK, United States of America and New Zealand found that participants in the UK consumed significantly more saturated fats and experienced the most challenges finding ingredients for food preparation compared with the other countries [5]. These studies all report on the potential impact on obesity; however, no studies are available that explore the effect of dietary changes due to lockdown on oral health.

Teesside is a county in the Northeast of England with among the highest levels of health deprivation in the UK [9], [10]. Communities in the Teesside have a lower-than-average life expectancy, and a significantly higher number of deaths due to suicide than the UK average. Teesside also has a high number of hospital admissions due to alcohol-related conditions and almost double the national average male deaths due to oral cancer [10]. The burden of oral diseases in this area is among the highest in the UK [11] and dental attendance is between $53 \%$ and $83 \%$ of adults attending a routine visit in the last two years [11].

Understanding the impact of the COVID-19 lockdown on 
oral health is critical for the future planning and commissioning of oral healthcare and public health services. Therefore, this study aimed to understand the dietary changes that occurred in this region due to the pandemic and lockdown and consequently its impact on oral health.

\section{METHOD}

This study followed a mixed-method approach utilizing a sequential exploratory design.

This study received ethical approval from the Teesside University School Research Ethics Sub-Committee (SRESC; \# 2021 Mar 2703 ENGLAND).

\section{A. Quantitative Survey}

An online questionnaire (see supplementary material) was developed from the World Health Organization (WHO) Oral Health Questionnaire (OHQ) for adults [12]. The WHO-OHQ has been already tested for validity and reliability and used globally to collect oral health data [13]-[17]. The online questionnaire included data about the participants' demographics and dietary habits before and during the lockdown.

Gatekeepers of community social media groups in Teesside were approached and asked to distribute the online questionnaire. Residents $\geq 18$ y living within Teesside were invited to participate in the survey. The survey was open from $12^{\text {th }}$ March $-12^{\text {th }}$ June 2021. Participation was voluntary, and the questionnaire's submission was considered valid consent; no financial reward was offered for participation.

The data were coded and descriptively analyzed using Statistical Package for the Social Sciences (SPSS) 25.0.24 Categorical variables were summarized and reported as frequency and percentage.

\section{B. Qualitative Survey}

Respondents to the quantitative survey were invited to contact the researcher to take part in a semi-structured interview. Consent was recorded verbally and stored on a password protected server at Teesside University. Semistructured interviews between 25-60 minutes in length were conducted via Microsoft Teams.

The interview guide (see supplementary material) was developed after the closing date of the quantitative survey to develop the interview guide based on the results. The interview guide contained 15 open ended questions relating to oral hygiene, nutritional choices, and access to oral healthcare during lockdown. The interview guide was pilot tested with two participants.

The data were collected utilizing a grounded theory method to identify emerging patterns from the participants thoughts and opinions. The interviews were transcribed verbatim and analyzed using NVivo12 software to identify common language among the participants which could be coded into themes and sub-themes (see supplementary material).

III. RESULTS

TABLE I: DEMOGRAPHIC DATA QUANTITATIVE

\begin{tabular}{|c|c|}
\hline Demographic data & Number $(\%)$ \\
\hline \multicolumn{2}{|l|}{$\overline{\mathrm{Sex}}$} \\
\hline Male & $26(12.8)$ \\
\hline Female & $177(87.2)$ \\
\hline \multicolumn{2}{|l|}{ Race and Ethnicity } \\
\hline $\begin{array}{l}\text { White -English / Welsh /Scottish / Northern } \\
\text { Irish/British }\end{array}$ & $179(88.2)$ \\
\hline $\begin{array}{l}\text { Any other ethnic background / Asian/ Black / } \\
\text { Caribbean / Arab }\end{array}$ & $24(11.8)$ \\
\hline \multicolumn{2}{|l|}{ Age Group } \\
\hline $18-29$ years & $34(21.0)$ \\
\hline $30-39$ years & $33(20.0)$ \\
\hline $40-49$ years & $42(26.0)$ \\
\hline $50-59$ years & $30(18.0)$ \\
\hline 60 and above years & $24(14.0)$ \\
\hline \multicolumn{2}{|l|}{ Education Level } \\
\hline GCSE's/ Vocational training/A-levels or equivalent & $64(31.7)$ \\
\hline Undergraduate degree & $72(35.6)$ \\
\hline Postgraduate degree & $64(31.7)$ \\
\hline \multicolumn{2}{|l|}{ Income Level } \\
\hline$<£ £ 16,000$ & $63(31.0)$ \\
\hline$£ 16,000-£ 29,999$ & $70(34.5)$ \\
\hline$£ 30,000-£ 59,999$ & $38(18.7)$ \\
\hline$£ 60,000$ - and above & $7(3.5)$ \\
\hline Rather not answer & $22(10.8)$ \\
\hline
\end{tabular}

The cross-sectional quantitative survey received 203 responses. Table I presents the demographic data of the responses. Most respondents were female $(87.2 \%)$, white ethnicity $(88.2 \%)$, aged $<50$ years $(67.0 \%)$, with an annual income $<£ 29,999$ a year $(65.5 \%)$ and holding an undergraduate or postgraduate degree $(65.5 \%)$. Tables II, III, IV present the effect of the pandemic on the frequency of consumption of fresh fruit; cakes and biscuits; sweets; sugar free gum; carbonated beverages; tea or coffee with sugar; fruit juice and smoothies; squash; water and alcohol.

TABLE II: FOOD CHOICES BEFORE AND DURING COVID-19 LOCKDOWN N (\%)

\begin{tabular}{|c|c|c|c|c|c|c|c|c|}
\hline & \multicolumn{2}{|c|}{ Fresh fruit } & \multicolumn{2}{|c|}{ Cakes } & \multicolumn{2}{|c|}{ Sweets } & \multicolumn{2}{|c|}{ SF gum } \\
\hline & Before & During & Before & During & Before & During & Before & During \\
\hline Every day & $62(30.7)$ & $55(27.5)$ & $38(18.9)$ & $50(25.3)$ & $17(8.6)$ & $29(14.9)$ & $16(8.1)$ & $8(4.1)$ \\
\hline Several times a week & $50(24.8)$ & $44(22.0)$ & $79(39.3)$ & $55(27.8)$ & $53(27.8)$ & $57(29.2)$ & $22(11.1)$ & $20(10.2)$ \\
\hline Once a week & $20(9.9)$ & $27(13.5)$ & $33(16.4)$ & $31(15.7)$ & $37(18.7)$ & $30(15.4)$ & $7(3.5)$ & $10(5.1)$ \\
\hline Several times a month/Seldom never & $15(7.4)$ & $23(11.5)$ & $40(19.9)$ & $41(20.7)$ & $85(42.9)$ & $38(19.5)$ & $143(72.2)$ & $146(74.5)$ \\
\hline Rather not answer & & & & & 1 & 1 & 3 & \\
\hline Total (n) & 202 & 200 & 201 & 198 & 198 & 195 & 198 & 196 \\
\hline
\end{tabular}


TABLE III: BEVERAGE CHOICES BEFORE AND DURING COVID-19 LOCKDOWN N (\%)

\begin{tabular}{|c|c|c|c|c|c|c|c|c|c|c|}
\hline & \multicolumn{2}{|c|}{ Carbonated drinks } & \multicolumn{2}{|c|}{ Tea with sugar } & \multicolumn{2}{|c|}{ Coffee with sugar } & \multicolumn{2}{|c|}{ Fruit juice/smoothies } & \multicolumn{2}{|c|}{ Squash } \\
\hline & Before & During & Before & During & Before & During & Before & During & Before & During \\
\hline 2-3 times a day & $14(7.1)$ & $16(8.1)$ & $11(5.7)$ & $14(7.3)$ & $12(6.1)$ & $\begin{array}{c}14 \\
(7.3)\end{array}$ & $2(1.0)$ & $3(1.6)$ & $\begin{array}{c}26 \\
(13.3)\end{array}$ & $\begin{array}{c}38 \\
(19.5)\end{array}$ \\
\hline Every day & $\begin{array}{c}21 \\
(10.6)\end{array}$ & $\begin{array}{c}28 \\
(14.2)\end{array}$ & $6(3.1)$ & $7(3.6)$ & $9(4.6)$ & $\begin{array}{c}10 \\
(5.2)\end{array}$ & $13(6.5)$ & $16(8.2)$ & $\begin{array}{c}42 \\
(21.4)\end{array}$ & $\begin{array}{c}39 \\
(20.0)\end{array}$ \\
\hline Several times a week & $\begin{array}{c}30 \\
(15.2)\end{array}$ & $\begin{array}{c}25 \\
(12.7)\end{array}$ & $12(6.2)$ & $8(4.1)$ & $7(3.6)$ & $9(4.7)$ & $\begin{array}{c}23 \\
(11.6)\end{array}$ & $\begin{array}{c}20 \\
(10.0)\end{array}$ & $\begin{array}{c}27 \\
(13.8)\end{array}$ & $\begin{array}{c}25 \\
(12.8)\end{array}$ \\
\hline Once a week & $\begin{array}{c}26 \\
(13.1)\end{array}$ & $\begin{array}{c}24 \\
(12.2)\end{array}$ & $4(2.1)$ & $2(1.0)$ & $1(0.5)$ & $2(1.0)$ & $16(8.0)$ & $19(9.5)$ & $12(6.1)$ & $11(5.6)$ \\
\hline RNA & & & & 1 & 2 & 1 & 1 & 3 & 2 & 1 \\
\hline Total & 198 & 197 & 194 & 193 & 197 & 193 & 199 & 194 & 196 & 195 \\
\hline
\end{tabular}

TABLE IV: ALCOHOL CONSUMPTION BEFORE AND DURING COVID-19 LOCKDOWN N (\%)

\begin{tabular}{ccc}
\hline \hline & Before & During \\
\hline \hline 4 or more times a week & $12(7.1)$ & $21(12.5)$ \\
2-3 times a week & $33(19.6)$ & $34(20.2)$ \\
Monthly or less & $42(25)$ & $30(17.9)$ \\
2-4 times a month & $41(24.4)$ & $34(20.2)$ \\
I do not drink & $16(9.5)$ & $16(9.5)$ \\
Never & $24(14.2)$ & $30(17.9)$ \\
Total & 168 & 168 \\
\hline \hline
\end{tabular}

In total nine participants agreed to be interviewed for the qualitative survey: 7 females and 2 males, aged between 26 and 50 years. Eight identified as White and one Black African. Thematic content analysis revealed themes and statements which explained the dietary choices the participants made during lockdown:

\section{A. Consumption of Fresh Fruit}

The frequency of participants consuming fresh fruit (Figure 1) regularly decreased $2-3$ times per day $(-1.7 \%)$, everyday $(-3.2 \%)$ and several times a week $(-2.8 \%)$. Meanwhile, increased in the once per week $(+3.6)$ and seldom never $(+4.1 \%)$.

P6: "Oh, probably got quite a lot of freezer stuff. Probably not so much fresh stuff because I don't like buying so much online because you can't see it... they tend to give you the stuff that's going to go out of date the next day"

\section{B. Cakes and Biscuits}

Participants consuming cakes and biscuits 2-3 times daily doubled during lockdown from $5.4 \%$ to $10.6 \%$, similarly those consuming them daily increased by $6.6 \%$. Consumption several times per week decreased by $11.5 \%$.

When describing the change to working from home multiple participants mentioned the increased consumption of sweet foods and snacking throughout the day to compensate for the lack of social interaction, they would normally have in their work environment.

P3: "The fridge is just downstairs for me. So, you're like fridge picking buying more snacks because I was working from home just, I probably eat more at home during the day than I did at work"

C. Sweets

The daily consumption of sweets almost doubled during lockdown, increasing from $8.6 \%$ to $14.9 \%$ and $2-3$ times daily from $2.5 \%$ to $4.6 \%$. Meanwhile, seldom/never decreased by $6 \%$.

P1: "So now obviously I've cut down a lot more. I've had to because I don't wanna get any bigger so I have lost half a stone, just by not eating sweets and stuff."

\section{Sugar-Free Chewing Gum}

Daily consumption of sugar-free chewing gum decreased by $50 \%$ from $8.1 \%$ to $4.1 \%$.

\section{E. Carbonated Drinks}

The daily consumption of carbonated drinks increased from $10.6 \%$ to $14.2 \%$.

Several participants noted that they consumed more carbonated beverages during lockdown and partly attributed this to working from home.

P8: "I mean I have tended to drink a lot fizzier juice and you know and in the past by I'm trying to cut it down because I know that is probably a large contribution towards my, my weight gain will be fizzy juice. If I were to cut it out it probably would lose a fair amount."

\section{F. Tea or Coffee with Sugar}

Frequent daily consumption (2-3 times) of tea with sugar increased from $5.7 \%$ to $7.3 \%$ and coffee with sugar increased from $6.1 \%$ to $7.3 \%$.

Participants discussed drinking more tea and coffee while working from home due to feeling tired and lethargic.

P3: "I think as I do a lot of team meetings and you know, yes, I've drank more coffee. So much more coffee. We go through a coffee so fast at the moment. I mean, that's, I feel 


\section{more lethargic."}

\section{G. Fruit Juice and Smoothies}

The daily consumption of fruit juice or smoothies increased from $6.5 \%$ to $8.2 \%$.

Participant 5 discussed the adverse effect of drinking smoothies and the advice they received to eat fruits whole.

"Sometimes I make a smoothie, but I tend to eat my fruit whole. I only realized that it's not good for you quite recently, to be honest."

\section{H. Squash (with or without added sugar)}

The most significant change in the consumption of squash 2-3 times daily, increasing from $13.3 \%$ to $19.5 \%$.

P6 mentioned their attempts to exchange carbonated beverages for water or squash: "it might be three or four sort of glasses this sort of size glass (holds up glass). Yeah, okay. Trying to have the same sort of amount of like water or like squash."

\section{Alcohol}

The most concerning result from the survey revealed that drinking alcohol $>4$ times per week increased from $7.1 \%$ to $12.5 \%$. The number of alcoholic drinks consumed 1-2 times daily increased from $34.4 \%$ to $36.8 \%$. Participants drinking $7-9$ drinks per sitting decreased from $3.7 \%$ to $2.7 \%$, and those drinking heavily ( $>10$ per day) remained unchanged.

Only participant 3 reported increased alcohol consumption during lockdown, all other participants responded that they did not, or rarely drank alcohol.

P3: "So yeah, we probably were drinking more during the week through lockdown because you know, that was sort of our escape?"

\section{Discussion}

The COVID-19 pandemic disproportionately affected the most disadvantaged communities. The Northeast of England suffered a $17 \%$ higher mortality rate due to COVID-19 compared with the rest of England and experienced longer lockdowns compared to the rest of the country, spending an additional 41 days in the harshest restrictions leading to a $55 \%$ increase in mental health disorders [18]. This study highlights the impact of COVID-19 lockdown on dietary choices made by individuals across the county.

A diet rich in varied fruit, vegetables, antioxidants, and vitamins is not a treatment for COVID-19, but it is a modifiable contributor towards noncommunicable diseases, which are highly associated with COVID-19 mortality and oral diseases [19]. When asked about the overall impact of lockdown on their oral health $37 \%$ of participants reported a negative effect. In contrast only $2.5 \%$ of participants reported an improvement in their oral health due to lockdown.

The pandemic induced a fear of food shortages, causing people to panic-buy and stockpile non-perishable food items with a longer shelf-life leading to a diet with poor nutritional value [20]. Results from this study demonstrate that participants reduced the frequency in which they were consuming fresh fruit and vegetables due to their reliance on supermarket delivery services, or relatives, understandably, the participants were anxious about visiting supermarkets unless it was essential. Additionally, unemployment in the
North was higher than the rest of the country during the pandemic and household income decreased from $£ 543.90$ to $£ 541.30$ per week [18] while the cost of fruit and vegetables were at an all-time high [21]. The demand for "food parcels" distributed by charitable organizations tripled in Teesside during the pandemic [22] although social support was provided by the government this should be distributed equitably to ensure the most deprived areas receive adequate support to maintain a basic standard of living.

The switch to unhealthy foods during the pandemic lockdown has been well documented [20]-[25] which is reflected in this study with participants increasing their daily consumption of sweets, cakes, and biscuits. Participants attributed this to the change in routine to working from home, and feelings of isolation working away from their colleagues where they have easy access to high carbohydrate snacks and drinks. Participants also discussed feelings of lethargy and linked this to their increased sugar consumption and poor diet leading to drinking more coffee during the day to stay awake. Dental biofilm converts available dietary sucrose into organic acids and when this process is frequently repeated leads to the demineralization of tooth enamel and eventually a cavity. Remineralization can occur through the washing action of saliva or chewing sugar free gum [26]. However, participants in this study also reported their daily intake of sugar free gum reduced, thereby creating an ideal intraoral environment for dental caries to occur. Although employers are increasingly aware of the need to address mental health issues, the lockdown presented new challenges in the way organizations support and communicate with their workers. Our research shows the need for remote digital support services and further research to encourage positive coping mechanisms.

A report by Public Health England indicated that alcohol related deaths increased by $20 \%$ during the lockdown as people turned to alcohol as a coping mechanism for stress, economic worries, and loneliness [27]. This study revealed that participants drank more frequently, however drank less in each sitting, whereas people drinking heavily $>10$ units per sitting remained unchanged. Alcohol misuse can lower immunity and increase the risk of severe COVID-19 infection [28], prolonged use, especially combined with tobacco consumption can increase the risk of oral and oropharyngeal cancer [3]. Therefore, it is essential that further research is conducted to understand which sociodemographic groups are increasing their alcohol use to create a targeted risk reduction strategy.

\section{LIMITATIONS}

While this study provides unique insights through both quantitative and qualitative data, it does have some limitations. The participants were recruited via social media, which may introduce bias towards people who are familiar with using technology. Data were collected nine-months after the first lockdown ended which may introduce recall bias, additionally, interview participants may have provided socially desirable answers. 


\section{CONCLUSION}

In summary, this research highlights the stark inequalities affecting Teesside which impacted upon the dietary choices made during the COVID-19 lockdown, which in turn can negatively affect oral health. The negative impact on oral and general health may be felt long after the return to "normality". There is a critical need to support this community during the current pandemic and into the future. Interventions should be co-designed to facilitate accepted strategies to tackle the burden of noncommunicable disease, especially the regional burden of oral diseases. The use of digital technologies should be considered to provide mental health and social support to individuals and families in lockdown.

\section{CONTRIBUtion OF Authors}

Conceptualization RE, LN, VZ; methodology RE, LN, VZ; data collections RE; analysis RE; original draft preparation RE; review and editing RE; LN; VZ. All authors have read and agreed to the published version of this manuscript.

\section{ACKNOWLEDGMENT}

The authors would like to thank the participants for their participation in this questionnaire during this challenging time.

\section{CONFLICT OF INTEREST}

Authors declare that they do not have any conflict of interest.

\section{REFERENCES}

[1] Moynihan P. The interrelationship between diet and oral health. Proc Nutr Soc. 2005; 64(4): 571-80.

[2] Scardina GA, Messina P. Good Oral Health and Diet. $J$ Biomed Biotechnol. 2012; 2012: e720692.

[3] Pelucchi C, Gallus S, Garavello W, Bosetti C, La Vecchia C. Cancer Risk Associated with Alcohol and Tobacco Use: Focus on Upper Aerodigestive Tract and Liver. Alcohol Res Health. 2006; 29(3): 193-8.

[4] Boris Johnson: You must stay at home. BBC News [Internet]. [cited 2021 Jun 19] Available from: https://www.bbc.com/news/av/uk52012581

[5] Murphy B, Benson T, McCloat A, Mooney E, Elliott C, Dean M, et al. Changes in Consumers' Food Practices during the COVID-19 Lockdown, Implications for Diet Quality, and the Food System: A Cross-Continental Comparison. Nutrients. 2020; 13(1): 20.

[6] Brondani B, Knorst JK, Tomazoni F, Dutra Cósta M, Vargas AW, Noronha TG, et al. Effect of the COVID-19 pandemic on behavioral and psychosocial factors related to oral health in adolescents: a cohort study. Int J Paediatr Dent. 2021; 31(4): 539-546.

[7] Pool E, Delplanque S, Coppin G, Sander D. Is comfort food really comforting? Mechanisms underlying stress-induced eating. Food Res Int. 2015; 76: 207-15.

[8] O'Connell M, Smith K, Stroud R. The dietary impact of the COVID19 pandemic [Internet] 2021 [cited 2021 Aug 8]. Available from: https://ifs.org.uk/publications/15503

[9] Wikipedia [Internet]. 2021 [cited 2021 Jun 19]. Available from: https://en.wikipedia.org/w/index.php?title=Tees_Valley\&oldid=1023 657144

[10] Tees Valley Vital Community Issues [Internet]. 2017 [cited 2021 Jun 19]. Available from: https://www.communityfoundation.org.uk/wordpress/wpcontent/uploads/2017/10/Vital-Issues-Vital-Issues-Tees-Valley-2017Healthy-Living.pdf
[11] Darlington Oral Health Plan 2017-2022 [Internet]. 2017 [cited 2021 Jun 12]. Available from: https://www.darlington.gov.uk/media/3730/oral-health-plan-2018.pdf

[12] Oral Health Questionnaire for Adults [Internet]. 1997 [cited 2021 June 12]. Available from: http://apps.who.int/iris/bitstream/handle/10665/41905/9241544937.pd f? sequence $=1$

[13] White DA, Tsakos G, Pitts NB, Fuller E, Douglas GVA, Murray JJ, et al. Adult Dental Health Survey 2009: common oral health conditions and their impact on the population. Br Dent J. 2012; 213(11): 567-72.

[14] Almazrooei B, Amir Rad F, Milosevic A. The Oral Health Status of Attendees and Residents in United Arab Emirates Care Homes. J Int Soc Prev Community Dent. 2020; 10(1): 101-6.

[15] Khoshnevisan MH, Albujeer ANH, Attaran N, Almahafdha A, Taher A. WHO's oral health assessment questionnaire for adult: psychometric properties of the Arabic version. J Contemp Med Sci. 2016; 2(8): 116-8.

[16] Singh A, Shrestha A, Bhagat TK, Baral DD. Assessment of oral health status and treatment needs among people of Foklyan area, Dharan, Nepal. BMC Oral Health. 2020; 20(1): 320.

[17] Lekic M, Dakovic D, Lazic Z, Cutovic T, Ilic I, Ilic M. The Serbian version of the Oral Health Questionnaire for Adults. Vojnosanit Pregl. 2020; (00): 9-9.

[18] Northern Health Science Alliance. A Year of COVID in the North report 2021 [Internet]. [cited 2021 Sep 20]. Available from: https://www.thenhsa.co.uk/app/uploads/2021/09/A-Year-of-COVIDin-the-North-report-2021.pdf

[19] Kamyari N, Soltanian AR, Mahjub H, Moghimbeigi A. Diet, Nutrition, Obesity, and Their Implications for COVID-19 Mortality: Development of a Marginalized Two-Part Model for Semicontinuous Data. JMIR Public Health Surveill. 2021; 7(1): e22717.

[20] Mattioli AV, Sciomer S, Cocchi C, Maffei S, Gallina S. Quarantine during COVID-19 outbreak: Changes in diet and physical activity increase the risk of cardiovascular disease. Nutr Metab Cardiovasc Dis. 2020; 30(9): 1409-17.

[21] Jayawardena R, Misra A. Balanced diet is a major casualty in COVID19. Diabetes Metab Syndr. 2020; 14(5): 1085-6.

[22] Murray K. Demand for food parcels triples across the Northeast during Covid-19 pandemic [Internet]. 2021 [cited 2021 Sep 20]. Available from: https://www.chroniclelive.co.uk/news/north-east-news/demandfood-triples-north-east-19906466

[23] Skrajnowska D, Brumer M, Kankowska S, Matysek M, Miazio N, Bobrowska-Korczak B. Covid 19: Diet Composition and Health Nutrients. 2021; 13(9): 2980

[24] Angelidi AM, Kokkinos A, Katechaki E, Ros E, Mantzoros CS Mediterranean diet as a nutritional approach for COVID-19. Metabolism-Clinical and Experimental. 2021; 114.

[25] Iddir M, Brito A, Dingeo G, Fernandez Del Campo SS, Samouda H, La Frano MR, et al. Strengthening the Immune System and Reducing Inflammation and Oxidative Stress through Diet and Nutrition: Considerations during the COVID-19 Crisis. Nutrients. 2020; 12(6): 1562.

[26] Lingstrom P, van Houte J, Kashket S. Food Starches and Dental Caries. Crit Rev Oral Biol Med. 2000; 11(3): 366-80.

[27] Surge in alcohol-related deaths during England lockdown, report finds. The Guardian [Internet]. 2021 [cited 2021 Sep 20]; Available from: https://www.theguardian.com/society/2021/jul/15/surge-in-alcoholrelated-deaths-in-england-during-lockdown-report-finds

[28] Factors associated with drinking behaviour during COVID-19 social distancing and lockdown among adults in the UK. Drug Alcohol Depend. 2021; 219: 108461. 